\title{
Learner-Centered Outcomes in Subject-Centered Institutions: Metaphors for Muggle Learning
}

\author{
Leon Fulcher
}

Zayed University, Abu Dhabi

Discuss this paper online at http://groups.yahoo.com/LTHE/

\begin{abstract}
Learner-centered education faces many challenges when introduced to university centers where faculty socialization into subject-centered teaching is the dominant ethos. Three warning metaphors drawn from the literature of $\mathrm{J} \mathrm{K}$ Rowling are used to illuminate challenges associated with learner-centered education. The first metaphor focuses attention on ways in which institutional structures in disciplinary education are frequently altered confronting faculty and students with organizational turbulence. The second metaphor warns that individual learners easily distracted from family and personal career goals. The final metaphor highlights ways in which learning - to be of value to students requires personal ownership and fit.
\end{abstract}

\section{Introduction}

Learner-centered education places emphasis on the learner and pays close attention to learning processes and outcomes, whereas subject-centered education emphasizes the content of disciplinary teaching inputs. The two orientations are substantially different. Learner-centered education faces many challenges when introduced to university centers where faculty socialization into subject-centered teaching is the dominant ethos. This means that many involved in university education still fail to distinguish between learning and teaching. It is comparatively easy for university teachers to stand in front of a class and tell students what they know. It is quite a different matter to engage students in disciplinary learning in such a way as to feel confident about their capacities to understand and absorb such learning then transfer it to situations outside the classroom.

This difference in academic cultures is exacerbated by other cultural differences. Learning is frequently impacted by competing views or "contestations" (Ibrahim 1998) between different cultural traditions. Faculty educated in Western traditions of scholarship are commonly guided by values and concepts that are framed by Euro-American cultural and language traditions (Fulcher 2003; Harrison 2003). When working with people who use English as a second language and come from different cultural traditions, it is easy to make false interpretations about human behaviour and family practices with substantially deleterious effects (Fulcher 2002). Culturally responsive practices (Ling 2001) rely on different sources of knowledge, often conveyed through the convention of metaphor (TaitRolleston et al 1997; Morgan 1986).

This paper uses three warning metaphors drawn from the literature of $\mathrm{J} \mathrm{K}$ Rowling to illuminate themes associated with learner-centered education. Specifically prepared for Muggles, or "non-magic" people (Rowling 1997), the core argument is that - as with the pop culture characters Harry Potter and his Hogwarts School friends - prospective graduates require dedicated periods of learner-centered education if they are to transfer learning from university classrooms to real-world workplaces. Ordinary "Muggle" professors have much to learn as they move from being university postgraduates and subject experts in specific disciplines to becoming learner-centered teachers with second language students. Along 
the way, learning through the use of metaphor may offer "Muggle" learners potential insights worthy of consideration

\section{Warning 1: “Watch Out For The Stairs, They're Always Changing!”}

In the first volume of Rowling's Harry Potter series (Rowling 1997) - while being taken to their residence halls on arrival at boarding school - First Year students were warned about the stairways at Hogwarts that are always changing so that students may end up in places they may least expect. Three decades of university teaching in the United Kingdom, New Zealand, Malaysia and now the United Arab Emirates has shown the present author how the institutional structures of disciplinary education are frequently altered through organizational re-structuring. Calls for enhanced effectiveness or efficiencies have commonly been put forward to justify administrative devolution, inter-disciplinary synergies or centralized budgetary control, resulting in both faculty and students being confronted with the unintended consequences of organizational turbulence. Having often struggled to understand one set of organizational ground rules or disciplinary teaching practices, students using English as a second language in particular find it difficult to understand the meaning of "deficiencies in the system" or "the need for enhanced institutional effectiveness" - almost always advanced as justifications for "corporate re-structuring" (Fulcher 1988).

This warning metaphor about the unintended consequences of re-structuring is not advanced because of fundamental opposition to organizational change. Indeed, organizational change is essential at periodic intervals to ensure that structures and processes remain consistent with institutional mandates and environmental realities. However, when faced with organizational turbulence and uncertainty, workers commonly retreat to principles and practices with which they are familiar (Fulcher 1994). Learnercentered and inter-disciplinary education is thus easily defined as inefficient in favor of disciplinary reaffirmation, whether measured by examination results, graduate employment rates or scholarly publications. Learner-centered education is all too easily characterized as esoteric and needlessly complicated, distracting attention away from the perceived goals of university education.

In the face of organizational turbulence, students are confronted with "ever-changing stairways" or learning pathways that may or may not take them to the post graduation destinations they or their families seek. This holds, regardless of assurances given by academic managers about restucturing efforts having no negative impact on student learning programs. Practical examples can be readily found in each instance of organizational restucturing - depending on whether managers are actually predisposed to consider them where the rhetoric of change falls far short of the realities experienced by those whose lives are impacted by restructuring. As Morgan (1986) so graphically showed, the "machine metaphor" of organizational functioning commonly used by many managers personifies staff as "replaceable parts" in an automated production line.

In the midst of change, some managers forget that effectiveness is an external measure associated with how well an organization achieves outcomes determined by community standards. Efficiency, on the other hand, is an internal measure associated with how well an organization performs identified tasks with a given quantum of resources. Both measures are important for modern universities but effectiveness remains the standard against which graduate learning is measured. All too often, the rhetoric of effectiveness is replaced by a pragmatic rhetoric along the lines of "seeing the process through regardless", a rallying cry that simply ignores short-term effects in support of the longer-term goals. Thus, the warning about watching out for the ever-changing stairways reminds us of the ends vs means debate in organizational change, posing questions about whether the ends always justify the means or whether individual student learning outcomes can be ignored altogether - regardless of the rhetoric. 


\section{Warning 2: "Beware Of Forces Trying To Knock One Off Course!"}

As first year students at Hogwarts School of Witchcraft and Wizardry, all students are introduced to Rowlings' imaginary game of Quidditch played on broomsticks in a large ovalshaped stadium. When introduced to the game, new students are warned to "watch out for the Bludgers", ball-shaped forces that try to knock them off course. Individual learners frequently find their attentions diverted away from personal, family and career goals while actively pursuing a university program of studies. Whether through illness or academic failure, family or peer group distractions or through the discovery of alternative interests, most university graduates cite examples of how their initial educational plans were altered through forces largely beyond their control.

In her classic study about predictable crises of adult life, Sheehy (1976) drew attention to ways in which personal "disruptions" to career paths are actually normative experiences for university students during their passages from adolescence to adult life. Far from being surprised when personal and social forces "disrupt" a young person's program of university study, those involved in tertiary education should ensure that support and academic advice are available to help ameliorate crises and promote active adaptation. This is why universities have established a range of student services aimed at the retention of students when faced with predictable life crises. It is also why many universities have appointed Advisors of Study for every student who enrolls. Considering that a typical full-time undergraduate spends roughly 15 hours per week in a university classroom (Levine 1994), the other 153 hours of the week are not likely to be shaped by subject-centered education, this in spite of personalized study within given disciplinary fields. Instead, family influences remain prominent for students living at home and peer group influences take on added significance for those living in university halls of residence.

In arguing for the need to achieve greater balance between rapid advances in knowledge and the needs of individual learners, Spring (1999) noted that "quality outcomes, not quality inputs were the key to economic success in a world increasingly open to free trade and competition. ... Education is not simply about preparing young people to take their place in a changing economy. It is about enlarging their minds, enlivening their imaginations, arousing their curiosity and assisting them in learning how to think" (pp. 183-185). Henchey asserted from a Canadian perspective that "what is important are the skills developed, the knowledge acquired and the values adopted, as well as the ability of learners to transfer and apply these skills, knowledge and values to a variety of situations in the real world" (1999, p. 266). In the context of human development and educational strategies for the United Arab Emirates, "proponents of change argue in favor of an 'outcome' approach to higher education whereby graduates emerge from the system with certain attributes which would equip them for the world of work" (Mograby 1999, p. 301). During times of rapid technological and social change, debates about the relative merits of learner-centered education compared with disciplinary excellence are largely irrelevant. Both themes are important and can only be confirmed through demonstrated learning outcomes transferred from classrooms to real-world workplaces.

Without personal ownership of learning, the forces operating to knock learners off course pose long-term implications for learners, families and communities. Muggle professors those without pretense of witchcraft or wizardry - need reminding that learner-centered education may impose challenging demands on their busy work schedules since they may have to engage all their students as "whole persons", not just erratic or even brilliant young scholars fired with enthusiasm for learning a particular subject.

\section{Warning 3: “Magic Wands Must Be Tailored To Each Person!”}

Having discovered that he had special skills and abilities, Harry Potter was still disbelieving about the prospect of being anything other than an ordinary young student with a willingness to learn. Only after finding he had been admitted to Hogwarts School of Witchcraft and 
Wizardry was Harry taken to be "fitted" for his magic wand. In that classic moment when Harry tested different wands for size, style and disposition, the storeman warned "no two wands are the same... and of course you never get such good results with another wizard's wand" (1997, p. 95). For our purposes, such a warning reinforces the idea that learning - to be of real value - requires personal ownership and fit. Five developmental rhythms are worth contemplating in respect of this notion of personal ownership and fit including: (i) family rhythms; (ii) educational, recreational and personal learning rhythms; (iii) rhythms of daily living; (iv) community and peer group rhythms; and (v) cultural or spiritual rhythms (Fulcher 2001).

Family Rhythms are closely associated with particular circumstances in each young person's home environment that may have shaped early learning and formative attitudes towards education. Family rhythms contribute to the socialization and behavioral training each child received before starting school and throughout their formal education. For these reasons, learner-centered education needs to seek active participation of family and extended family members throughout the educational process. Family connections and rhythms are closely associated with each child's sense of identity (Bronfenbrenner, 1979), playing a key role in shaping a unique personal and social character. In cultural contexts where family obligation is given greater priority than individual commitments, then family rhythms must be a part of personalized programs of study. Whether involving UAE Bedouin family members or New Zealand Maori elders in university education, such involvement has yielded enhanced learning outcomes for second language students from these respective communities when compared with reliance on traditional Western approaches that focus exclusively on performance of individual students.

Educational, recreational and personal learning rhythms include both formal and informal rhythms associated with a student's capacity for learning, their formal educational activities and achievements, and recreational pursuits (Small \& Fulcher, 1985). These rhythms connect young people to a peer group, giving opportunities for behavioral, social and cultural learning so important to long-term development, learning and achievement (Maier 1987). Young people who have experienced predictability in caring and learning rhythms learn to trust and emotionally depend on personal relationships with teachers and others (Maier 1979). Through thus managing relationships with students, the emphasis can shift from institutional controls and processes to personalized learning and the complementary development of leisure time activities tailored to each young learner (Garfat, 1998). Multiple learning opportunities promote personalized learning that is sensitively planned around the developmental needs and performance of each student.

Second language students in the UAE recently illustrated this point when describing how their teacher set assignments involving personalized research and weekly written reflections about learning. What appeared on the face of it to be a positive, learner-centered approach was dismissed by students who explained that having enrolled in three different courses offered by the same professor, they found the same assignments for each course. No attempt had been made to consider the students' whole program of study with the result that students complained of boredom with the same assignments in three different courses. Their course workloads focused little on them as individuals. In spite of good intentions, their professor focused on course learning inputs and not the integration of meaningful learning outcomes for students. The rhetoric of learner-centeredness and the reality of subject-centered practice were thus once again highlighted.

Rhythms of daily living, whether at home, in a residence hall or other shared living arrangements involve daily and weekly rhythms associated with eating, sleeping, working or playing, all of which impact on the transfer of learning from classrooms to workplaces. Rhythms of group living can be identified through an examination of weekly routines and activities, recognizing ways in which weeknight and weekend activities can impact on learning. Whether a student arrives at class in the morning having had breakfast or a good night's sleep can make substantive differences to their capacity for learning. Family 
tensions, crises or bereavements also impact on learning. Monthly and seasonal rhythms also feature, as with school, work and mid-term holiday periods. Schools sponsored by religious organizations frequently employ weekly, monthly and seasonal rituals, or as found in Islamic countries, religious practices require daily prayers and annual periods of fasting.

Such rhythms are closely associated with learning outcomes achieved by students during their educational careers. This point was highlighted by one group of 14 university students enrolled in courses taught by this author while writing this paper. Major illness impacted 3 students, serious family illness/injury or bereavement for a family member impacted 3 others, family disruption through marital problems or separation impacted 2, while preparations for marriage or assistance with family wedding arrangements impacted 2 others. This meant that over 70 percent of the class experienced substantial life changes in their daily living arrangements which impacted on learning outcomes achieved across 4-5 different courses during the same semester!

Learner-centered education needs also to engage with community and peer group rhythms. Responsive education may require that students be given opportunities for purposeful engagement in social experiences that reinforce normative peer group activities (Fahlberg 1991; Halverson 1995). Some young people, especially those with experiences of family upheaval, have had their community and peer group rhythms disrupted as family decisions are made without thought for unintended consequences on educational performance. As children are moved from one setting to another, or change schools, it follows that relationships with friends are severed. Unless new relationships are formed then educational performance for some children and young people suffers. Rhythms associated with peer group and communities of interest are often linked to learning outcomes achieved by young people and the extent to which these benefit both students and their families (Maier 1990).

Finally, one cannot ignore cultural and spiritual rhythms that operate informally as well as formally in responsive educational programs. Tae (2000) confirmed how the formal education system for Malay children is founded upon informal education practices that reinforce cultural practices and Islamic teachings in Malaysia. Elsewhere (Fulcher 1998; Tait-Rolleston et al 1997) cultural rituals of encounter were described as being commonly overlooked in the delivery of educational and child and youth care services. A close examination of interactions between teachers and students serves to highlight a variety of cross-cultural themes. This theme is highlighted each year during the Holy Month of Ramadan at any university in Islamic countries, as well as for Muslim students attending university in any Western country. The taking of food or drink is restricted for students during daylight hours, and in Islamic countries the teaching periods are shortened from onehour to half an hour, and the teaching day is shortened accordingly. In most Western countries, the academic year is timetabled around Christmas and Easter holiday periods, a rhythm particularly absent in Islamic countries. Structural features such as these reinforce the need for university teachers to have minimal cross-cultural competencies if they are are to avoid significant gaffes that leave some students feeling culturally unsafe (Leigh 1998).

\section{Conclusion}

In conclusion, there are good reasons for learner-centered education being supported and safeguarded in disciplinary-based institutions. Organizational re-structuring in the name of enhanced effectiveness or efficiencies need not abandon learning outcomes because of faculty unease with learner-centered education. It is easy to throw the baby out with the bathwater when re-configuring institutional strategies and re-shaping disciplinary boundaries in the face of inter-disciplinary challenge. As seen in the three Rowling "warning metaphors", change is a feature of modern universities and both personal and social forces will continue to shape student career paths. Unless students achieve ownership of learning that transfers outcomes from classrooms to real-world workplaces, educators will receive little justification for their continuing activities. As non-magic people or Muggles, it is only 
through engaging with students in learning relationships that personalized learning outcomes are achieved.

\section{References}

Bronfenbrenner, U. (1979). The Ecology of Human Development. Cambridge: Harvard University Press.

Fahlberg, V. (1991). A Child's Journey Through Placement. Indianapolis, Indiana: Perspective Press.

Fulcher, L. C. (1988). The Worker, The Work Team And The Organisational Task. Wellington: Victoria University Press.

Fulcher, L. C. (1994). When You're Up To Your Neck In Alligators, It's Hard To Remember That The Original Aim Was To Drain The Swamp!: Lessons From New Zealand Health Sector Reform. Australian Social Work, Vol 47, No 2, pp. 47-53.

Fulcher, L. C. (1998). Acknowledging Culture in Child and Youth Care Practice, Social Work Education. Vol 17, No 3, pp. 321-338.

Fulcher, L. C. (2001). Managing the Soul, Rhythms and Blues of Child and Youth Care, Journal of Child and Youth Care Work. Vol 15-16: pp. 30-49.

Fulcher, L. C. (2002). Cultural Safety and the Duty of Care, Child Welfare. Vol LXXXI, No 5, pp. 689-708.

Fulcher, L. C. (2003). The Working Definition of Social Work Doesn't Work Very Well in China and Malaysia. Research on Social Work Practice. Vol 13, No 3, pp. 376-387.

Garfat, T. (1998). The Effective Child and Youth Care Intervention: A Phenomenological Inquiry, Journal of Child and Youth Care. Vol 12, No 1-2.

Halverson, A. (1995). The Importance of Caring and Attachment in Direct Practice with Adolescents. Child and Youth Care Forum. Vol 24, No 3, p. 169.

Harrison, G. (2003). Language, Difference and Diversity: Bilingual Perspectives in Social Work. Brisbane: University of Queensland, unpublished PhD Thesis.

Henchey, N. (1999). The Future of Education and Work: A Perspective from Canada. In Education and the Arab World: Challenges of the Next Millennium, Abu Dhabi: The Emirates Center for Strategic Studies and Research, pp. 243-268.

Ibrahim, Z. (Ed). (1998). Cultural Contestations: Mediating Identities In A Changing Malaysian Society. London: ASEAN Academic Press.

Leigh, J. W. (1998). Communication for Cultural Competence. Sydney: Allyn and Bacon.

Levine, A. (Ed.) (1994). Higher Learning in America: 1980-2000. Baltimore: The Johns Hopkins University Press.

Ling, H. K. (2001). Towards Developing Culturally Appropriate Social Work Practice: Insights From A Study Of Help-Seeking And Help-Giving Experiences in Sarawak, Malaysia. Brisbane: The University of Queensland: Unpublished PhD Thesis.

Maier, H. W. (1987). Developmental Group Care of Children and Youth: Concepts and Practice. New York: The Haworth Press.

Maier, H. W. (1979). The Core of Care: Essential Ingredients for the Development of Children at Home and Away From Home, Child Care Quarterly. Vol 8, No 3, pp. 161-173.

Maier, H. W. (1990). A Developmental Perspective for Child and Youth Care. In J Anglin, C Denholm, R Ferguson \& A Pence, eds, Perspectives in Professional Child and Youth Care. Binghamton, New York: The Haworth Press, pp. 7-24. 
Mograby, A. (1999). Human Development in the United Arab Emirates: Indicators and Challenges. In Education and the Arab World: Challenges of the Next Millennium, Abu Dhabi: The Emirates Center for Strategic Studies and Research, pp. 279-307.

Morgan, G. (1986). Images of Organization. London: Sage Publications.

Rowling, J. K. (1997). Harry Potter and the Philosopher's Stone. London: Bloomsbury Publishing Plc.

Sheehy, G. (1976). Passages: Predictable Crises of Adult Life. New York: E P Dutton.

Small, R. \& Fulcher, L. C. (1985). Teaching Competence in Group Care Practice. In L C Fulcher \& F Ainsworth, eds, Group Care Practice With Children. London: Tavistock Publications, pp. 135-154.

Spring, G. (1999). Future Schools: Getting the Balance Right. In Education and the Arab World: Challenges of the Next Millennium, Abu Dhabi: The Emirates Center for Strategic Studies and Research, pp. 183-201.

Tae, H. S. (2001). Informal Education and Cultural Learning in Malaysia: A Case Study from Kelantan. Victoria University of Wellington, New Zealand. Unpublished MA Thesis.

Tait-Rolleston, W., Cairns, T., Fulcher, L. C., Kereopa, H. and Nia Nia, P. (1997). He Koha KiiNa Kui Ma, Na Koro Ma: A Gift Of Words From Our Ancestors, Social Work Review. Vol 9, No 4, pp. 16-22.

\section{About the Author}

Dr Leon Fulcher is a New Zealander of American ancestry appointed Assistant Dean in the College of Family Sciences at Abu Dhabi after 17 years with Victoria University of Wellington in New Zealand, 10 years with the University of Stirling in Scotland and visiting appointments in Malaysia and China. 